\title{
VARIASI BAHASA PADA TAYANGAN KICK ANDY DALAM EPISODE "NGELMU SAMPAI MATI"
}

\author{
Fitri Puji Rahmawati* dan Sumarlam** \\ Program Doktor Pendidikan Bahasa Indonesia \\ Universitas Sebelas Maret Surakarta \\ |*fitri_pr@ums.ac.id \\ **sumarlamwd@gmail.com
}

\begin{abstract}
Abstrak
Penelitian ini bertujuan untuk mendeskripsikan literasi wujud variasi bahasa yang terdapat dalam tayangan Kick Andy episode "Ngelmu sampai Mati". Metode yang digunakan adalah deskriptif kualitatif. Penyediaan data dilakukan dengan metode simak dengan menyimak dan memahami data-data kebahasaan yang berupa data lisan dalam sumber data tayangan Kick Andy. Tekniknya adalah teknik rekam dan teknik catat. Analisis data menggunakan metode padan. Hasil penelitian mendeskripsikan bahwa wujud variasi bahasa dalam tayangan ini terdiri dari variasi dari segi keformalan, penutur, penggunaan, dan sarana. 1) Variasi segi keformalan menggunakan ragam santai dan akrab, 2) variasi penutur banyak diwarnai dialek betawi dan batak, 3) register bidang pendidikan banyak mewarnai dalam variasi penggunaan, dan 4) sarana lisan digunakan dalam variasi sarana pada tayangan ini.
\end{abstract}

Kata Kunci: literasi, variasi bahasa, kick andy

\begin{abstract}
This study aims to describe the literary form of language variation contained in the show Kick Andy episode, "Learn to Death". The method used is descriptive qualitative. Provision of data is done by methods refer to listen and understand the data linguistic oral form of data in the data source view Kick Andy.The technique is a recording and log techniques. The analysis of data using a unified method. The research result describe that form of language variation in this show consists of variations in terms of formality, speakers, use, and means. 1) The variation in terms of formality using a variety offamiliar, 2) variations Betawiand Batak dialect speakers are used, 3) variations in the use of more use of registers in the field of education, 4) Variation means used in this show is a variation of oral.
\end{abstract}

Keywords: literacy, language variation, kick andy

\section{Pendahuluan}

Sebuah tayangan atau tontonan masyarakat merupakan bagian dari melihat fenomena kehidupan masyarakat saat itu yang sedang berkembang. Kehidupan ini mencakup juga kebahasaan masyarakatnya dalam situasi dan kondisi masyarakat. Tayangan televisi yang tengah menjadi tren, 
akan diikuti dengan gaya bahasa baru yang akan berkembang di masyarakat. Oleh sebab itu, perlu kajian terhadap tayangan televisi, tidak hanya berdasarkan isi kandungan acara, namun juga penggunaan bahasanya.

Talkshow merupakan salah satu jenis acara di radio atau televisi yang isi acaranya membahas suatu topik tertentu dengan menghadirkan bintang tamu yang dipandu oleh seorang pembawa acara. Tamu yang diundang biasanya berasal dari tokoh-tokoh yang memiliki keunikan, prestasi, pengalaman yang luas, idola, atau tokoh masyarakat yang terkait dengan isu yang sedang diperbincangkan. Acara ini dibawakan oleh pembawa acara dengan santai namun bermakna.

Talkshow Kick Andy bersifat menginspirasi atau memberikan warna lain dari kehidupan seseorang. Acara ini merupakan salah satu dari program unggulan Metro TV yang dipandu oleh Andy Flores Noya. Talkshow ini ditayangkan live setiap hari Jumat pukul 21.30 hingga 22.30 WIB dan disiarkan ulang pada hari Minggu pukul 13.05 WIB. Talkshow ini disiarkan perdana pada tanggal 01 Maret 2006 sampai sekarang. Tema yang dihadikan oleh Kick Andy selalu menarik dengan menghadirkan kisah kehidupan nyata yang informatif, edukatif dan menginspirasi, karena tujuan dari talk show ini adalah mencerdaskan bangsa melalui kisah-kisah inspiratif yang didatangkan langsung dari narasumber.

Literasi memiliki definisi (lama) yakni kemampuan membaca dan menulis ( $7^{\text {th }}$ Edition Oxford Advanced Learner's Dictionary, 2005: 898 dalamAlwasilah, 2012: 159). Perkembangan definisi literasi sangat pesat, saat ini kata literasi telah disandingkan dengan banyak ragam keilmuan lain, seperti: literasi virtual, literasi komunikasi, literasi komputer, literasi matematika, dan lain sebagainya. Terkait dengan objek kajian studi literasi yang bertumpang tindih dengan banyak bidang ilmu, literasi tetap berurusan dengan penggunaan bahasa dan kajiannya merupakan kajian lintas disiplin yang memiliki tujuh dimensi yang saling terkait, yakni: dimensi geogrfis, bidang, keterampilan, fungsi, media, jumlah, dan bahasa.

Dimensi jumlah merujuk pada banyak hal, misalnya bahasa, variasi bahasa, peristiwa tutur, bidang ilmu, media, dan sebagainya. Multitalerat mampu berinteraksi dalam berbagai situasi. Kemampuan tersebut tumbuh karena proses pendidikan yang berkualitas tinggi. Literasi, seperti halnya komunikasi, bersifat relatif (Alwasilah, 2012: 161-163).

Artikel ini akan mendeskripsikan tentang literasi dalam dimensi jumlah yang ditekankan pada variasi bahasa yang terdapat dalam tayangan talkshowKick Andy pada episode "Ngelmu sampai Mati". Tinjauan yang dilakukan termasuk dalam kajian sosiolinguistik.

Sosiolinguistik adalah bidang ilmu antardisiplin yang mempelajari bahasa dalam kaitannya dengan penggunaan bahasa itu di dalam masyarakat (Chaer, 2004:2; Suwito, 1985: 2). Ilmu yang dipelajari antara lain struktur sosial dan proses-proses sosial, termasuk di dalamnya perubahanperubahan sosial (Alwasilah, 1993:1). Struktur dan proses sosial yang dipelajari tidak lepas dari adanya dua aspek tingkah laku manusia yakni penggunaan bahasa dan organisasi tingkah laku manusia (Fishman, Giglioli (1972) dalam Ohoiwutun, 2007:9). Penggunaan bahasa di tengah masyarakat yang saling bersosialisasi menghasilkan situasi-situasi bahasa yang bervariasi. Satu bahasa dengan bahasa yang lain akan sangat mempengaruhi, sebagaimana pernyataan Bram dan Dickey (dalam Ohoiwutun, 2007:9) bahwa sosiolinguistik berupaya menjelaskan kemampuan manusia menggunakan aturanaturan berbahasa secara tepat dalam situasisituasi yang bervariasi. Nababan (1986) merumuskannya dengan kajian yang berhubungan dengan penutur bahasa sebagai anggota masyarakat. Situasi yang terbentuk 
merupakan dorongan-dorongan sosial yang memicu penggunaan variasi bentuk bahasa di tengah lingkungan yang beraneka ragam.

Hartmann dan Stork (1972 dalam Alwasilah, 1993, p.37) menyatakan bahwa sekelompok orang biasanya pada tempat yang sama, berbicara ragam bahasa yang sama, atau bahasa baku yang sama. Sekelompok orang ini kemudian akan menunjukkan kesepakatan dan kaidah penggunaan bahasa yang berkaitan dengan aspek budaya dalam masyarakatnya (Sumarsono, 2002; Wijana, 2010, p.11). Berdasarkan pernyataan ini dapat ditarik pernyataan bahwa setiap individu adalah anggota masyarakat ujaran dalam batasan satu dialek. Jika seseorang memiliki verbal repertoire yang luas, maka dia akan mampu berkomunikasi dengan beberapa dialek atau ragam bahasa lain. Hartman dan Stork membedakan variasi bahasa ini berdasarkan kriteria (a) latar belakang geografi dan sosial penutur, (b) medium yang digunakan, dan (c) pokok pembicaraan (dalam Chaer dan Agustina, 1995, p.81).

Chaer \& Agustina (1995, p.81) mengatakan bahwa variasi atau ragam bahasa dilihat sebagai akibat adanya keragaman sosial penutur bahasa dan keragaman fungsi bahasa. Variasi bahasa terbagi menjadi berbagai jenis, antara lain variasi dari segi penutur, pemakaian, keformalan, dan sarana.

a. Variasi dari segi penutur meliputi idiolek, dialek, sosiolek, dan kronolek. Idiolek adalah ujaran individu yang unik dimiliki oleh perseorangan (Alwasilah, 1993, p.42). Dialek merupakan suatu ragam bahasa yang dikaitkan dengan sekelompok penutur tertentu dan saling mengerti dengan ragam-ragam lainnya (Wardhough, 1972 dalam Alwasilah, 1993, p.43). Sosiolek adalah variasi bahasa yang berkenaan dengan status, golongan, dankelas sosial para penuturnya. Kronolek atau dialek temporal yaitu variasi bahasa yang digunakan oleh kelompok sosial pada masa tertentu.

b. Variasi dari segi pemakaian.

Variasi bahasa berkenaan dengan penggunaannya, pemakaiannya, atau fungsinya yang disebut fungsiolek, ragam, atau register. Variasi ini dibicarakan berdasarkan bidang penggunaan, gaya, atau tingkat keformalan, dan sarana penggunaan. Variasi bahasa berdasarkan bidang pemakaian ini adalah menyangkut bahasa itu digunakan untuk keperluan atau bidang apa, misalnya bidang sastra, perikanan, jurnalis.

c. Variasi dari segi keformalan yang terbagi menjadi ragam beku, ragam resmi, ragam usaha, ragam santai, dan ragam akrab.

Ragam beku adalah variasi bahasa yang paling formal, yang digunakan dalam situasi-situasi khidmat dan upacaraupaca resmi. Ragam resmi atau formal yaitu variasi bahasa yang digunakan dalam pidato kenegaraan, rapat dinas, surat-menyurat dinas, ceramah keagamaan, buku-buku pelajaran, dan sebagainya. Ragam bahasa usaha (konsultatif) adalah ragam bahasa yang digunakan dalam pembicaraan biasa di sekolah dan rapat. Ragam santai adalah ragam yang digunakan dalam situasi santai. Ragam bahasa akrab adalah ragam bahasa yang digunakan antara teman yang sudah akrab, karib, dan keluarga.

d. Variasi dari segi sarana dilihat dari sarana yang digunakan. Berdasarkan sarna yang digunakan dibagi menjadi dua, yakni ragam bahasa lisan dan tulisan. Ragam bahasa lisan disampaikan secara lisan dan dibantu oleh unsur-unsur suprasegmental, sedangkan ragam bahasa tulis unsur suprasegmental tidak ada.

Variasi bahasa merupakan sejenis ragam bahasa yang pemakaiannya 
disesuaikan dengan fungsi dan situasinya, tanpa mengabaikan kaidah-kaidah pokok yang berlaku dalam bahasa yang bersangkutan. Berdasarkan pemahaman ini, variasi atau ragam bahasa tidak bisa mengesampingkan faktor nonlinguistik selain faktor linguistiknya.

Penelitian sosiolinguistik yang mengamati pemakaian bahasa pernah dilakukan oleh Saddhono (2012) denganjudul "Kajian Sosiolingustik Pemakaian Bahasa Mahasiswa Asing dalam Pembelajaran Bahasa Indonesia untuk Penutur Asing (BIPA) di Universitas Sebelas Maret" yang mendeskripsikan bahwa mahasiswa asing yang belajar bahasa Indonesia di UNS mempunyai kekhasan dalam pemakaian bahasa dalam berkomunikasi. Dalam percakapan sehari-hari masih banyak dipengaruhi oleh BING karena alat mediasi bahasa yang paling mungkinkan bagi mahasiswa asing dan dosen. Akan tetapi karena tuntutan agar dapat menggunakan bahasa Indonesia mereka berusaha mengunakannya walaupun masih banyak tuturan yang tidak sesuai dengan konteks walaupun secara kebahasaan sudah sesuai. Bahasa ibu atau bahasa asli mahasiswa asing kadang-kadang ma-sih mempengaruhi dalam mereka bertutur, terutama dalam bidang fonologi. Oleh karena UNS terletak di kota Solo yang mempunyai bahasa pengantar bahasa Jawa maka banyak tuturan mahasiswa asing yang dipengaruhi bahasa Jawa. Pengajar bahasa Indonesia untuk orang asing harus juga mengajarkan bahasa Indonesia berdasarkan tempat dan konteks sosialnya selain bahasa Indonesia ragam baku. Dengan demikian, mahasiswa asing tidak akan banyak mengalami kesulitan ketika berkomunikasi dalam masyarakat sehari-hari. Sebaiknya dalam pengajaran bahasa Indonesia untuk orang asing disesuaikan juga dengan konteks sosialnya bukan sekadar bahasa Indonesia formal.

\section{Metode Penelitian}

Bentuk dan strategi penelitian ini terarah pada penelitian kualitatif yang bersifat deskriptif. Penelitian ini mengarah pada pendeskripsian secara rinci dan mendalam mengenai hal-hal yang ditemukan dalam sasaran penelitian. Jenis penelitiannya adalah penelitian dasar, yang bertujuan untuk memahami suatu masalah yang mengarah pada manfaat teoretik (Sutopo, 2006, p.136). Pemilihan jenis penelitian dasar disesuaikan dengan tujuan yang ingin dicapai pada penelitian ini yaitu diperolehnya pemahaman bagi pembaca atau masyarakat mengenai kebahasaan di tayangan Kick Andy.

Pada penelitian ini akan dikaji tentang penggunaan bahasa sebagai sarana komunikasi sosial, yang pelaksanaannya mengandalkan manusia (peneliti) sebagai instrumen pengumpul data. Peneliti mengumpulkan data yang berwujud wacana talkshow yang mencakup kalimat, gugus kalimat, alinea, penggalan wacana, dan wacana utuh. Selanjutnya satuan lingual itu dideskripsikan sesuai dengan variasi bahasa yang terdapat di dalamnya. Metode ini dikenal sebagai metode deskriptif, yaitu metode dengan menggunakan teknik mencari data, mengumpulkan, menganalisis, dan mengelompokkannya berdasarkan fenomena-fenomena yang ada.

Data yang digunakan dalam penelitian ini adalah wacana talkshowKick Andy yang tayang di Metro TV dengan presenter Andy F.Noya dalam tema "Ngelmu sampai Mati". Sumber data yang digunakan dalam penelitian ini berupa teks. Sumber data yang dimaksud dalam penelitian ini adalah hasil rekaman dan salinan teks acara talkshow Kick Andy yang direkam dari youtube. Penyediaan data dilakukan dengan metode simak. Metode simak dalam penelitian ini adalah menyimak dan memahami data-data kebahasaan yang berupa data lisan dalam tayangan Kick Andy 
Tekniknya adalah teknik rekam. Teknik rekam digunakan oleh peneliti untuk merekam acara Kick Andy dari youtube. Teknik selanjutnya adalah teknik catat. Data yang telah diunduh ditulis agar dapat mempermudah analisis kebahasaan.

Analisis data menggunakan metode padan. Metode padan yang sesuai untuk penelitian ini adalah subjenis referensial dan subjenis translasional (Sudaryanto, 1993). Hasil penelitian disajikan dengan metode informal. Metode informal dengan uraian menggunakan kata-kata biasa meskipun dengan terminologi yang teknis sifatnya.

\section{Hasil Penelitian dan Pembahasan}

Kick Andy adalah sebuah program talk show yang dipandu oleh wartawan senior Andy F. Noya di Metro TV. Acara ini disiarkan perdana pada tanggal 1 Maret 2006. Hingga saat ini, Kick Andy menjadi salah satu tayangan favorit dan inspiratif bagi masyarakat Indonesia. Program ini mengudara setiap hari Jumat pukul 20:05 WIB dan ditayangkan ulang pada hari Minggu pada pukul 13:30 WIB.

Adapun gaya dan cara penyampaian program ini mirip dengan acara Oprah yang dibawakan oleh Oprah Winfrey. Bahkan, Andy F. Noya sendiri awalnya ragu bisa membawakan acara ini. Acara ini menyajikan kisah kehidupan nyata yang informatif, edukatif dan inspiratif. Tamu atau narasumber yang diundang dari kalangan manapun, tidak ada batasan tertentu sehingga banyak cerita seru dan tak teduga seputar kehidupan masyarakat seluruh Indonesia yang dibagi dalam acara tersebut.

Dalam pembawaannya, Andy F. Noya selaku host mempunyai karakter dan gaya bahasa yang unik dan khas. Dalam setiap poin pertanyaan yang bersifat langsung, formal, dan jujur namun tidak sarkastik terkadang mengundang tawa sehingga para narasumber merasa nyaman dan terbuka ketika menjawab pertanyaan yang dilontarkan.
Di akhir acara, Kick Andy biasanya membagi-bagikan buku gratis karangan tokoh ternama dan best seller kepada para penonton yang hadir di studio. Tak jarang pula, Kick Andy mengundang band, penyanyi solo, atau musisi. Dalam situs resmi Kick Andy, Bung Andy, sapaan akrab Andy F. Noya, menuturkan bahwa konsep dasar tayangan tersebut adalah untuk mengasah hati para penontonya.

Literasi pada dimensi jumlah yang memfokuskan pada variasi bahasa mendeskripsikan bahwa berbagai wujud variasi bahasa digunakan oleh penutur dan mitra tutur dalam tayangan ini. Penutur dalam dialog adalah Andy F. Noya yang berperan sebagai pemandu acara Kick Andy, penutur tambahan adalah Dr. Paulus, putra dari Diana Patricia Pasaribu Hasibuan, dan narator yang menambahkan riwayat hidup tamu dalam acara ini. Mitra tutur pada acara ini adalah Diana Patricia Pasaribu Hasibuan, dosen STT Ekumene Jakarta yang menyelesaikan pendidikan S3 pada usia 77 tahun. Ibu Diana telah mengantongi tiga rekor MURI.

Wujud variasi bahasa yang kaya menjadi bukti kemampuan literasi dari si penutur terutama di bidang kebahasaan. Andy F. Noya merupakan tokoh pemandu acara yang telah lama berkecimpung di dunia entertainmen, bertemu dengan banyak tokoh dari berbagai kalangan sangat membekali kemampuan Andy dalam menggunakan berbagai bahasa/multibahasa.

\subsection{Variasi bahasa dari segi keformalan} Ragam bahasa yang digunakan pada talkshow Kick Andy adalah ragam bahasa santai dan akrab. Ragam bahasa ini digunakan dengan tujuan mengasah hati penontonnya, sehingga perlu teknik agar komunikasi tersebut dapat dipahami dan diambil maknanya, acara ini dikemas dengan santai dan akrab. Hal ini terlihat pada tuturan yang akrab dan santai dari penutur maupun mitra tuturnya. Berikut ini tuturan yang 
memperlihatkan penggunaan variasi bahasa atau ragam santai.

(TO1-1) Tadi sepintas sudah saya perkenalkan Ibu Diana Patricia Pasaribu Hasibuan. Ibu Diana dalam usianya yang menjelang 80 tahun itu tercatat sebagai pemegang rekor MURI tiga rekor. Ya, bu ya... Ibu, ini kan mengagumkan dalam usia itu karena rekor yang dipegang adalah rekor sarjana S1 tertua yang dicatat oleh rekor MURI.

Emang waktu lulus sarjana umur berapa, Ibu?

(TO1-10) Ibu Diana ngajar apa sekarang?

(TO2-10) Sekarang lagi mengajar pada semester ini ada dua mata kuliah pengantar Perjanjian Lama dan Filsafat Pendidikan.

Ragam bahasa santai merupakan ragam bahasa yang digunakan pada situasi santai. Talkshow Kick Andy merupakan salah satu talkshow yang dikemas dengan ragam ini. Kosakata dalam ragam bahsa santai ini banyak dipenuhi unsur leksikal dialek. Salah satu contoh tuturan dalam talkshow Kick Andy yakni penggunaan kata emang 'memang', ngajar 'mengajar', dan lagi 'sedang'. Ketiga kata ini dipengaruhi oleh dialek yang dipergunakan penutur. Kata emang dipengaruhi oleh penggunaan dialek Betawi yang berarti 'memang' demikian juga kata lagi yang berarti 'sedang' merupakan dialek Betawi.. Kata ngajar yang berasal dari mengajar kemudian dihilangkan awalan me merupakan pengaruh dialek Jawa.

\subsection{Variasi bahasa dari segi penutur}

Variasi atau ragam dari segi penutur tampak pada penggunaan dialek Jakarta/ Betawi yang sering dipakai oleh Andy maupun Diana untuk menimbulkan kesan akrab, sebagaimana terlihat pada tuturan berikut ini.
(TO1-16) Tunggu... tunggu... tunggu.... kenapa suami ngajarin untuk memperlihatkan kartu mahasiswa.

(TO1-21) Tapi sejak sejak saat itu, Ibu tetap pake atau....

(TO1-22) Tunggu Bu, saya nggak denger dengan baik tadi. Sampai di rumah ibu ngomong apa ke is... suami....

(TO2-23) Gak pake, malu.... Karena... selama jalan saya di... melotot saja kondektur itu sama saya

(TO1-30) Ibu jangan bohong nih?

(TO2-30) Begini, pernah sekali waktu kami... sudah mau... mau... waktu itu hari ujian sudah dibagi kursi di Katolik sangat strenght. Saya bilang teman sebelum dosen belum datang dan belum membagian... membagiakan soal ujian, lalu saya bilang teman di kanan saya. Eh, boleh ndak kita buku...buka buku sebelum. Terus dia jawab saya, tentu aja karena saya sudah tua, kita kan harus jujur ibu. Padahal saya tidak menyontek tidak apa waktu itu, hanya saya bilang boleh ndak buka buku sebelum ujian? Kita kan harus jujur, Ibu.... Jadi tapi kata jujur itu selalu ...oh ya... jujur ber... teriang di hati saya kata jujur itu adalah kata yang indah.

Dialek yang masuk ke dalam proses komunikasi ini sering terjadi pada proses komunikasi yang santai. Kata ngajarin, pake, nggak pake, gak pake, ngomong, nih, ndak merupakan beberapa kata dari dialek Betawi.

Ragam atau variasi bahasa akrab/ intimete juga mewarnai tuturan Dr. Paulus ketika mengutarakan kebanggannya pada Sang Ibu. Berikut ini tuturannya. 
(TO4-1) Memang e... batas usia pensiun, biasanya kemampuan berpikir, kemampuan untuk belajar menurun. Tetapi Mamak masih mempunyai power untuk itu. Itu jadi pertama, rasa bangga. Yang kedua, memang e... eh... tadi bilang takut kalau Mamak tiba-tiba sakit. Dia manusia yang kondisi seperti itu bisa sakit macam-macam. Tapi itu tadi karena mungkin Allah tidak tidur jadi diberi kesehatan terus sama Tuhan

Ciri dari ragam akrab ini, antara lain: terdapat sapaan khusus, penggunaan bahasanya tidak lengkap dan pendek-pendek namun dapat dipahami mitra tutur. Pada tuturan di atas, Dr. Paulus menyapa Sang Ibu dengan kata mamak. Kata mamak merupakan sapaan akrab yang mungkin sudah terbiasa digunakan di keluarga untuk menyamakan dengan sapaan ibu, mama, emak, bunda, dan sebagainya.

\section{Kalimat "Memang batas usia} pensiun, biasanya kemampuan berpikir, kemampuan untuk belajar menurun." Merupakan kalimat yang tidak lengkap. Kalimat ini tidak memiliki objek yang dikenai, hanya memenuhi fungsi predikat saja. Hal ini menjadi bukti ragam akrab sebab kalimat ini tidak lengkap namun diketahui siap yang dituju sebagai objek tuturan.

\subsection{Variasi bahasa dari segi penggunaan}

Variasi bahasa dari segi penggunaan tampak pada penggunaan register. Register merupakan ragam bahasa tertentu yang digunakan untuk maksud tertentu, sebagai balikan dari dialek sosial atau regional (Alwasilah,1993:63). Register yang tampak pada komunikasi yakni register di bidang pendidikan. Bentuk register tampak pada tuturan berikut ini.

(TO2-28) Seolah-olah kata mereka dosen juga, seolah-olah kenapa ini diterima seolah-olah juga dosen kurang yakin eee... bahwa saya itu kuliah. Tetapi waktu UTS seorang dosen profesor memanggil saya ke depan yang lain tidak dipanggil. Ibu Patricia katanya diambil lembaran hasil ujian. Selamat yan bu dikasih selamata rupanya saya dapat delapan tujuh setengah. Aaa, sesudah itu baru temen mahasiswa diam tidak ada lagi yang me....

(TO1-29) Nah, ini saya mau tanya $\mathrm{Bu}$, mahasiswa kan ada kebiasaaan nyontek, Ibu pernah menyontek enggak?

(TO2-30) Begini, pernah sekali waktu kami... sudah mau... mau... waktu itu hari ujian sudah dibagi kursi di Katolik sangat strenght. Saya bilang teman sebelum dosen belum datang dan belum membagian... membagiakan soal ujian, lalu saya bilang teman di kanan saya. Eh, boleh ndak kita buku...buka buku sebelum. Terus dia jawab saya, tentu aja karena saya sudah tua, kita kan harus jujur ibu. Padahal saya tidak menyontek tidak apa waktu itu, hanya saya bilang boleh ndak buka buku sebelum ujian? Kita kan harus jujur, Ibu.... Jadi tapi kata jujur itu selalu ...oh ya... jujur ber...

(TO3-1) Menuntut ilmu tidak berbatas waktu, itulah prinsip yang dipegang teguh Diana Patricia Pasaribu Hasibuan. Wanita yang akrab disapa Diana ini, memasuki bangku kuliah di usia senja yaitu 65 tahun. Keinginan kuat dalam diri Diana, mendorongnya mendaftar sendiri kuliah jenjang strata satu di sekolah tinggi filsafat Driyakara, Jakarta. Lulus di usia 69 tahun, wanita yang 
lahir di Tapanuli Utara 79 tahun silam ini merasa belum puas dan memutuskan untuk melanjutkan pendidikan hingga jenjang tertinggi. Di usia 73 tahun Diana lulus pascasarjana dari Intitiut Teologi dan Keguruan Jakarta dan mendapat gelar doktor dari STT Bettle Indonesia di usia 77 tahun. Dalam menyelesaikan tugas kuliah, Diana mengaku tidak pernah dibantu oleh siapapun, ia selalu setia dengan mesin tik tuanya ini. Sibuk dengan aktivitas perkuliahan tidak membuat ibu 6 orang anak ini melupakan tugasnya sebagai ibu rumah tangga. Diana sering mendapat dukungan dari suami dan semua anaknya.

(TO4-1) Memang e... batas usia pensiun, biasanya kemampuan berpikir, kemampuan untuk belajar menurun. Tetapi Mamak masih mempunyai power untuk itu. Itu jadi pertama, rasa bangga. Yang kedua, memang e... eh... tadi bilang takut kalau Mamak tiba-tiba sakit. Dia manusia yang kondisi seperti itu bisa sakit macam-macam. Tapi itu tadi karena mungkin Allah tidak tidur jadi diberi kesehatan terus.

(TO3-2) Karena kegigihannya dalam menuntut atau menimba ilmu, nenek dari 12 orang cucu ini tiga kali mendapat penghargaan dari MURI. Kini Diana menjadi dosen tetap di STT Ekumene Jakarta. Bagi Diana, ilmu yang ia dapatkan harus ia bagi agar bermanfaat bagi masyarakat.

Register pendidikan yang mewarnai percakapan antara Andy dan Diana terjadi karena konteks pembicaraan dalam acara ini adalah ngelmu (belajar) sampai mati. Beberapa rangkaian kata yang khas ada dalam dunia pendidikan digunakan, seperti: UTS, delapan tujuh setengah, menyontek, dibagi kursi, buka buku, menuntut ilmu, bangku kuliah, jenjang strata satu, jenjang tertinggi, pascasarjana, gelar, batas usia pensiun, menuntut atau menimba ilmu, dan dosen tetap.Kata dan frasa tersebut secara spontan digunakan sebab antara penutur dan mitra tutur dapat saling memahami atau bisa jadi memiliki latar belakang yang sama, yakni pernah mengenyam dunia pendidikan, sehingga meskipun si penutur (Andy) menanyakan dengan register pendidikan yang dibuatnya, si mitra tutur (Diana) tetap bisa memahami pertanyaan tersebut dan menjawabnya secara tepat.

\subsection{Variasi bahasa dari segi sarana}

Variasi ini dilihat dari sarana yang digunakan. Berdasarkan sarana yang digunakan dalam acara talkshow Kick Andy, maka dapat disimpulkan variasi bahasanya termasuk dalam ragam lisan. Ragam ini disampaikan secara lisan dan dibantu oleh unsur-unsur suprasegmental.

\section{Simpulan}

Literasi variasi bahasa pada tayangan talkshow Kick Andy episode "Ngelmu sampai Mati" terkait dengan penggunaan bahasa atau tuturan dari $\mathrm{O} 1$ atau penutur dan O2 yakni mitra tutur menyimpulkan bahwa terdapat variasi bahasa yang beragam. Variasi bahasa ini dapat dibedakan dalam empat variasi, yakni: dari segi keformalan, penutur, penggunaan dan sarana. Variasi bahasa dari segi keformalan tampak pada penggunaan ragam bahasa santai dan akrab yang dituturkan oleh Andy sebagai pemandu acara maupun Diana sebagai mitra wicara. Ragam ini dipilih, terutama oleh penutur sebagai pengarah berjalannya percakapan, semata-mata untuk membuat acara menjadi segar dan ringan, terkesan akrab. Segi penutur, variasi bahasa yang terlihat adalah penggunaan dialek. Dialek yang mewarnai dalam bahasa mereka adalah 
dialek betawi dan batak. Variasi bahasa dari segi penggunaan, penutur dan mitra tutur menggunakan register pendiidkan. Hal ini terjadi karena ranah pembicaraan dan latar belakang mitra tutur berasal dari pendidikan. Variasi bahasa dari segi sarana, tayangan ini menggunakan variasi lisan.

\section{Daftar Pustaka}

Alwasilah, A. Chaedar. (1993). Pengantar Sosiologi Bahasa. Bandung: Penerbit Angkasa.

-------. (2012). Pokoknya Rekayasa Literasi. Bandung: Kiblat.

Chaer, A dan Leoni A. (2004).Sosiolinguistik: Perkenalan Awal. Jakarta: Rineka Cipta.

Hymes, Dell. (1997). "The Scope of Sociolinguistics" dalam Nikolas Coupland dan Adam Jaworski (Ed.) Sociolinguistics: A Reader and Coursebook. United States of America: Macmillan Press Ltd.

Nababan, P.W.J. (1986). Sosiolinguistik: Suatu Pengantar. Jakarta: Gramedia.

Ohoiwutun, Paul. (2007). Sosiolinguistik: Memahami Bahasa dalam Konteks Masyarakat dan Kebudayaan. Jakarta: Visipro.

Saddhono, Kundharu. (2014). "Kajian Sosiolingustik Pemakaian Bahasa Mahasiswa Asing dalam Pembelajaran Bahasa Indonesia untuk Penutur Asing (BIPA) di Universitas Sebelas Maret". Dalam Jurnal Kajian Linguistik dan Sastra, vol. 24, no.2., hlm. 176186.

Sudaryanto. (1993). Metode dan Aneka Teknik Analisis Bahasa: Pengantar Penelitian Wahana Kebudayaan secara Linguistis. Yogyakarta: Duta Wacana University Press.

Sumarsono dan Paina Partana. (2002). Sosiolinguistik. Yogyakarta: Pustaka Pelajar.

Suwito. (1985). Sosiolinguistik Pengantar Awal. Surakarta: Henary Offset.

Wijana, I Dewa Putu. (2006). Sosiolinguistik: kajian Teori dan Analisis.Yogyakarka: Pustaka Belajar. 